This item was submitted to Loughborough's Research Repository by the author.

Items in Figshare are protected by copyright, with all rights reserved, unless otherwise indicated.

\title{
The use of actor-based immersive health and safety inductions: Lessons from the Thames Tideway Tunnel megaproject
}

\section{PLEASE CITE THE PUBLISHED VERSION}

https://doi.org/10.1016/j.apergo.2019.102955

\section{PUBLISHER}

Elsevier

VERSION

AM (Accepted Manuscript)

\section{PUBLISHER STATEMENT}

This paper was accepted for publication in the journal Applied Ergonomics: Human factors in technology and society and the definitive published version is available at https://doi.org/10.1016/j.apergo.2019.102955.

LICENCE

CC BY-NC-ND 4.0

\section{REPOSITORY RECORD}

Harvey, Eleanor, James Pinder, Roger Haslam, Andrew Dainty, and Alistair Gibb. 2019. "The Use of Actorbased Immersive Health and Safety Inductions: Lessons from the Thames Tideway Tunnel Megaproject". Loughborough University. https://hdl.handle.net/2134/9850379.v1. 


\section{The use of actor-based immersive health and safety inductions: Lessons from the Thames Tideway Tunnel megaproject}

Eleanor J. Harvey ${ }^{1}$, James A. Pinder ${ }^{1}$, Roger A. Haslam²(Corresponding Author), Andrew R. J. Dainty ${ }^{1}$, Alistair G. Gibb ${ }^{1}$

\section{Author Affiliations}

1. School of Architecture, Building and Civil Engineering, Loughborough University, Loughborough, Leicestershire, LE11 3TU, UK

2. School of Design and Creative Arts, Loughborough University, Loughborough, Leicestershire, LE113TU, UK

\section{Contact Details}

Eleanor Harvey - E.J.Harvey@Lboro.ac.uk

James Pinder - J.A.Pinder@Lboro.ac.uk

Roger Haslam - R.A.Haslam@Lboro.ac.uk

Andrew Dainty - A.R.J.Dainty@Lboro.ac.uk

Alistair Gibb - A.G.Gibb@Lboro.ac.uk 


\title{
The use of actor-based immersive safety and health inductions: Lessons from the Thames Tideway Tunnel megaproject
}

\begin{abstract}
Health and safety inductions are ubiquitous in construction but tend to be poorly designed and suffer low levels of worker engagement. In this paper we report on the evaluation of an innovative, full day, actor-based health and safety induction called EPIC, currently being used on London's Thames Tideway Tunnel megaproject. As of March 2019, more than 14,000 individuals had attended EPIC. This evaluation examines the impact of EPIC from the perspective of participants and other stakeholders, and considers the utility of actor-based immersive health and safety inductions for use more widely, in both construction and other sectors. Using a mixed-method, longitudinal approach to data collection, EPIC is evaluated against Kirkpatrick's (1959) 'four levels' framework of reactions, learning, behaviour change and results. This paper discusses factors which support and hinder actor-based inductions, and the challenges involved in assessing the impact of inductions on subsequent behaviour and health and safety outcomes.
\end{abstract}

\section{Keywords}

Construction; Health and Safety; Onboarding; Sociotechnical Systems; Training Evaluation. 


\section{Introduction}

\subsection{Background}

Occupational safety and health $(\mathrm{OSH})$ inductions are briefings given to workers when they start work on a new site or project. Such inductions have become commonplace in construction and workers on most projects in most countries of the world experience an induction in one form or another whenever they move to a new project, which may be very frequently. In an industry with a poor $\mathrm{OSH}$ record and a largely itinerant workforce, $\mathrm{OSH}$ inductions are used to 'orientate' new workers (Levitt and Samuelson, 1993) and help them to familiarise themselves with hazards they may encounter when working on a new construction site. In some countries, such as the United Kingdom (UK), OSH inductions are mandatory on all construction projects.

However, even though $\mathrm{OSH}$ inductions are ubiquitous in construction, surprisingly little research has been conducted into how they are perceived by workers, whether they are effective at improving OSH on site, or what makes for an effective (or ineffective) induction. Furthermore, when OSH inductions have been discussed in the literature, they are usually mentioned (very briefly or in passing) as part of a broader study of site $\mathrm{OSH}$, rather than as a topic of interest in their own right. A number of studies (e.g. Sawacha et al., 1999; Langford et al., 2000) that sought to identify factors associated with safety on construction sites found that $\mathrm{OSH}$ inductions are, to varying degrees, positively correlated with better safety on site, but they did not (or could not) explain how or why this is the case. There is thus no theoretical underpinning for understanding or implementing an induction strategy, and no basis for establishing whether practice established in other sectors resonates within a construction project context.

One of the few studies to shed light on contemporary induction practices in construction was by Pink et al. (2010), who reported on the findings of an ethnographic study of inductions on construction sites around the UK. The ethnographic researchers observed problems that will be familiar to anyone who has been through a site induction, including: Low levels of 
engagement from trainers and workers - particularly workers with low-level understanding and communication of English language; poor and inconsistent communication of complex health and safety information; a failure to establish whether learning outcomes had been achieved; and a lack of open discussion of risks and hazards. Pink et al. (2010) concluded that the requirements of training and briefing were conflated in inductions to the detriment of both agendas, and that these functions should be separated.

Recognising the problems inherent in conventional site inductions, some clients and contractors have tried different approaches to orientating construction workers, including the use of induction software. This paper reports on the evaluation of an innovative and awardwinning actor-based induction called EPIC ${ }^{1}$, which is being used on a major infrastructure project in the UK: the Thames Tideway Tunnel (Tideway) megaproject in London. The authors led a three-year, multi-disciplinary research study on Tideway, funded by the Institution of Occupational Safety and Health (IOSH). As Davies et al (2014, p.35) noted "The UK megaproject ecosystem was and remains a fertile ground for innovation." Nevertheless, innovation on megaprojects remains "surprisingly under-explored in the megaproject management literature" (Sergeeva and Zanello, 2018, p.1068).

EPIC was designed to teach inductees the interpersonal skills needed to challenge unsafe practices and establish the values of the project, empowering them to make a difference on site. EPIC is therefore about 'socialisation' (Wilson, 2012) - the process by which newcomers learn to fulfil their role in an organisation, both in terms of practical skills and softer values and expected behaviours (Van Maanen \& Schein, 1979). Poor socialisation has been found to lead to lower performance, satisfaction and commitment, and increased employee turnover (Phillips, Esterman, \& Kenny, 2015). However, despite this, most conventional OSH inductions tend to focus on ensuring compliance with rules (Daskalaki, 2012) rather than socialisation. EPIC, by contrast, puts an emphasis on the culture expected on the project, which is more

\footnotetext{
${ }^{1}$ EPIC is an abbreviation of Employer Project Induction Centre
} 
reflective of the notion of onboarding being about "indoctrinating new employees into the organizational culture" (Cable et al., 2013; p.23).

In temporary multiple organisations (TMOs) - such as construction megaprojects - disparate groups of workers from different organisations come together for short and variable periods of time; these organisational boundaries create additional cultural challenges and complexities when managing OSH (Harvey, Waterson and Dainty, 2018). Despite this, research on onboarding and socialisation has tended to focus on describing specific practices used by permanent organisations to induct permanent employees (Klein, Polin, \& Leigh Sutton, 2015; Graybill, Carpenter, Offord, Piorun, \& Shaffer, 2013) - thus, ignoring the size, structure, culture, leadership, communication and job design of the work in question (Ashforth \& Saks, 1996).

Researching how temporary employees (or workers) can be effectively socialised in TMOs is a novel and valuable endeavour (Batistič \& Kenda, 2018; Lundin and Söderholm, 1995), and the need to consider the context of this process is clear. Culture, organisational processes, and worker readiness, training, and socialisation are some of the many originating influences contributing to construction accidents (Haslam et al., 2005). This research takes a sociotechnical systems (STS) appraoch to evaluating actor-based inductions, with a view to understanding the complex interactions between this technology, its human participants, and its wider context (Waterson, 2015; Wilson, 2014).

\subsection{Actor-based training}

The use of actors in training and inductions is still relatively novel in the construction industry, however actor-based training has been used for several decades in other fields, most notably in healthcare and social work as part of scenario-based training. For instance, actors have been employed to simulate patients in clinical consultation coaching (Wilson, 2000), to play the part of anaesthetists in the training of surgical teams (Kassab et al., 2010) and to role play 
in child protection training (Lexton et al., 2005). Most of the published research on the use of actors in training and inductions has taken place in these fields.

Authenticity is by far the most widely cited advantage of actor-based training because trained actors have the skills and confidence to portray roles realistically and improvise when required (Bell et al., 2014). This can make for a much more immersive and interactive learning experience (Keltner et al., 2011). In her study on using actors in social work simulations, Petracchi $(1999$, p. 67) found that "Social work students began to conceptualize and to "feel" how a social worker would react in a given situation rather than simply imagining the actions that would take place."

At the same time as providing greater realism, actor-based training can also provide a "safe environment" in which to learn (Bell et al., 2014). Actors can portray roles in ways that are sensitive and non-threatening (Finn, 2014; Lexton et al., 2005), a particularly important issue when discussing topics that are emotive, such as child protection and mental health. Actorbased training can also make for a more consistent learning experience, because actors can play the same role again and again, whilst adapting their responses to a particular group of learners (Petracchi, 1999).

Nevertheless, actor-based learning also has some disadvantages including the difficulty and time required to set-up such training (Keltner, 2011), and the cost of employing and training actors (Bell et al., 2014). Lexton et al. (2005) found that using actors in child protection training doubled the cost of running a course. There is also a risk that using actors in simulated training may perpetuate stereotypes or appear patronising to experienced professionals (Lexton et al., 2005). More experienced professionals may find the acting less realistic than their less experienced peers, which may impact on their learning experience (Nestel et al., 2008). Finally, a lack of long-term evaluations means the power of actor-based training to effect sustained behavioural change is unknown. 
The aim of our evaluation was to examine the impact of EPIC from the perspective of participants and other stakeholders, and to consider whether actor-based immersive OSH could be used more widely, in both construction and other sectors. In the next section of this paper we describe the context for our evaluation and the methods used to evaluate EPIC. We then present the findings from our evaluation and discuss the broader themes that emerged from the research. The paper concludes by discussing the lessons learned from this evaluation of EPIC and what these lessons mean for the design and implementation of other OSH inductions.

\section{Methodology}

\subsection{Study context}

Tideway is a $£ 4.2$ billion project set up to construct a new 'super sewer' to serve London's growing population and to prevent sewage overflow polluting the River Thames. Tideway is being delivered over an eight-year period, across multiple construction sites in central London and involves three joint-venture consortia of principal contractors. The joint-ventures (JVs) are each delivering a different part of the project and a fourth contractor will be responsible for delivering the control system for the project.

EPIC was developed following an initial proposal from Active Training Team Ltd (ATT) and a competitive tender process, through which the client (Tideway) appointed an actor-based training provider. EPIC built upon previous immersive, behaviour-based $\mathrm{OSH}$ training programmes, including a one-off initiative on another megaproject in the UK, and is the second stage in a broader onboarding process (Figure 1). Before attending EPIC, all new workers attend a Central Onboarding Facility (COF) that deals with security and access, drugs and alcohol testing, health examinations and an $\mathrm{OSH}$ communications assessment. Following EPIC, and before they start work on site, all site-based workers attend a site induction held by the principal contractors. 


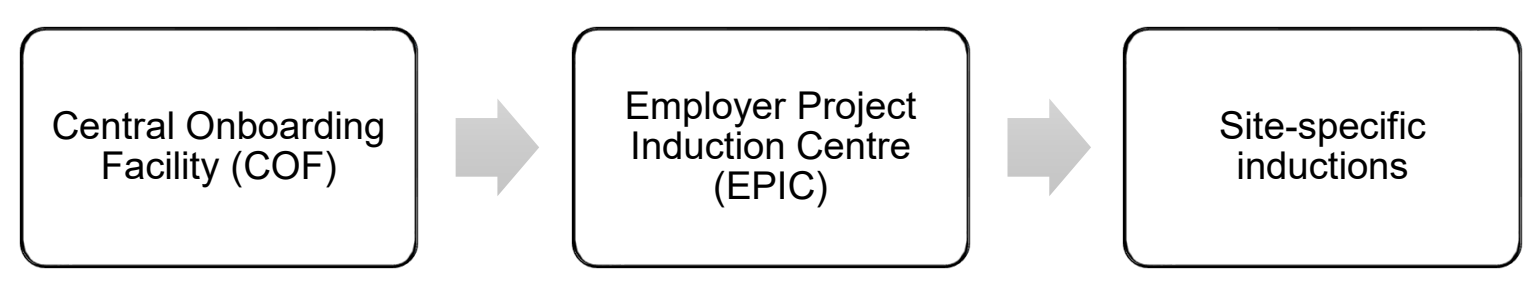

Figure 1: Overview of the Tideway onboarding process

The research presented in this paper is part of a broader longitudinal study of OSH practices at Tideway. The study was conducted between February 2016 and January 2019 and sought to understand how OSH policies, practices and interventions on a complex project unfold over time as they are influenced by different agendas and pressures. Our longitudinal study of OSH practices at Tideway involved a variety of research methods, including interviews with a broad cross-section of people working on the project, focus groups with front-line workers, observation of meetings and events, and reviewing project documentation. Key OSH policies - including EPIC, onboarding, and training - were tracked throughout the duration of the research. Pettrigrew's (1992) strategy process research approach, was followed, which allowed for an evaluation of the effects of various interventions over time, including the ways in which they were appropriated and re-appropriated through and by the contexts within which they were enacted. This is particularly important for evaluating the longer-term effectiveness of EPIC. A more detailed discussion of the methods, benefits and challenges of the longitudinal research can be found in Fuller et al. (2017).

\subsection{Data collection methods}

When evaluating training, Pulley's (1994) theory of 'Responsive Evaluation' stresses the need to put the objectives of the training and needs of the trainees above the need for evaluation avoiding methods which could be intrusive or compromise the session. In terms of data collection, sensitivity to context is key and thus a mixed-methods approach is recommended (Newby, 1992). Participants' subjective impressions of the impact of an intervention must be 
triangulated with other data about external factors that may have influenced its effect (The Scottish Government, 2015).

Measurements of behaviour often rely on self-report questionnaires which are highly subjective - compromising their validity (O'Conner et al., 2002). Exit questionnaires following training typically ask about participants' satisfaction and enjoyment, yet there is no evidence to suggest a positive experience corresponds with learning (Holton, 1996; O'Conner, Flin, Fletcher \& Hemsley, 2002) or subsequent behaviour change (Warr, Allan \& Birdi, 1999). Alliger \& Janak (1989) found people often mistake good presentation for learning and give poor ratings if the message of the training is difficult. Specifically in terms of evaluating inductions, Anderson, Cunningham-Snell and Haigh (1996) found the means of evaluation has a significant impact inductees' satisfaction - with participants giving higher satisfaction ratings on an exit questionnaire compared to other methods.

In accordance with Newby's (1992) endorsement of a mixed-methods approach to training evaluation, data were analysed from interviews, focus groups, observations, proposal and design documents, media articles and exit feedback forms. These sources, detailed below, together allowed for triangulation to improve the validity of the findings. Furthermore, using multiple sources allowed the study of EPIC's impact longitudinally by gathering perceptions from those who had been working on the project for some time. This dataset builds a rich picture of EPIC, allowing commonalities and contradictions in the data to be identified.

The data collection method informing our evaluation included:

- 128 semi-structured interviews conducted with a wide-range of stakeholders, from members of the project's senior leadership team through to workers on site. These interviews were carried out between February 2016 and January 2019 and explored a variety of OSH topics, including EPIC.

- 14 focus groups with front-line workers on the same topics, carried out in May and June 2017, and January 2018. 
- 12 participant observations of EPIC, with each member of the research team attending EPIC and documenting their first-hand experiences as 'normal' delegates. Each member attended on a different day to experience the actors playing different roles and responding to different cohorts of attendees.

- Project documentation relating to EPIC, including the initial concept design and subsequent tender documents.

- 530 paper exit feedback forms collected at the end of the course between June and July 2016.

- 2,927 exit feedback responses collected on electronic keypads at the end of the course between February 2018 and December 2018.

- 224 responses to an online survey of mainly office-based staff working on the Tideway project conducted in September and October of 2016. The survey comprised a mix of open-ended and closed (rating scale) questions about $\mathrm{OSH}$ at Tideway and the onboarding process, including questions relating specifically to EPIC.

- 12 articles publicising EPIC in the media including reviews by practitioners and news about the awards it has won.

Both exit feedback surveys were created and administered by the training provider responsible for EPIC. A new set of exit questions were introduced by the training provider in 2018 , to inform their key-performance indicators, hence the results of the two exit surveys are not directly comparable. A response rate for these surveys is not available but was observed by researchers to be high (approximately $80 \%$ ).

\subsection{Data analysis}

Interviews and focus groups were audio-recorded, transcribed verbatim, and initially analysed by deductively coding content relevant to each topic in NVivo qualitative analysis software. This enabled all data concerning EPIC and the onboarding process to be collated. The 
transcripts, observations, documents, exit feedback, survey responses, and media articles relating to EPIC and onboarding were then coded inductively.

\subsection{Analytical framework}

The immediate impact of induction on participants, either positive or otherwise - is often examined with post-session feedback questionnaires. However, the effect of induction over time is more complex and much less frequently considered: It is these temporal effects that are of greatest interest. Kirkpatrick's (1959) seminal 'Four Levels' model of training evaluation (Kirkpatrick and Kirkpatrick, 2006) suggests that training should be assessed based on whether participants: react favourably; learn new skills; apply these in the way they behave; and ultimately, whether the training achieves the desired results.

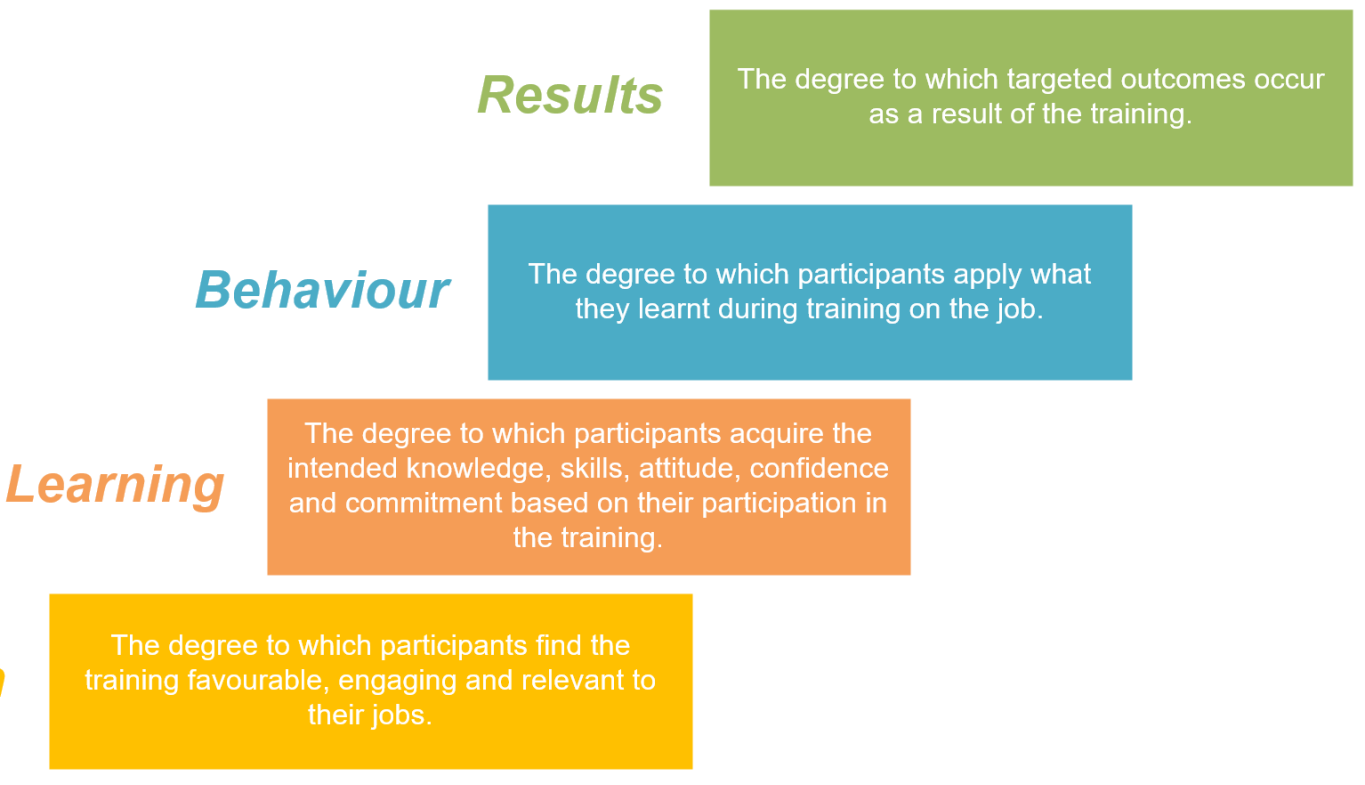

Figure 2: Kirkpatrick's 4 levels of training evaluation (Kirkpatrick and Kirkpatrick, 2006)

Its focus on evaluating training outcomes in the immediate, medium and long-term has been developed in many subsequent models (e.g. Hamblin, 1974; Kaufman, Keller \& Watkins, 1995; Warr, Bird \& Rackham, 1970). 
Criticisms of the Four Levels hinge on the model's assumption of causal links between the levels and therefore that learning is a linear process (Alliger \& Janak, 1989; Bates, 2004; Kraiger \& Aguinis, 2013). The notion that learning is a complex process has influenced later models of training evaluation - accounting for formative feedback (Bernthall, 1995) and advocating a holistic view of evaluation as part of an iterative process of improvement (Bushnell, 1990; Stufflebeam, 2003). For instance, the UK's National Institute for Health and Care Excellence recommends evaluating behaviour change programmes not only on their effectiveness, but also acceptability, feasibility, equity and safety (NICE, 2007); thus, rather than focussing on the outcomes of training, evaluation seeks a "compelling chain of evidence" (Kirkpatrick and Kirkpatrick, 2009, p.6) between every aspect of the training's planning, design, development, delivery and objectives.

Our growing understanding of the complexity of learning has also significantly influenced the nature of training since the 1950s when Kirkpatrick's research was conducted: formal teaching styles are considered outdated, and instead pedagogical best-practice emphasises personalised and experiential learning (Fry, Ketteridge, \& Marshall, 2014; Kolb, 1987). This is another reason the Four Levels are less applicable to contemporary training. Kraiger \& Aguinis (2013) argue the effectiveness of learning is affected by situational and individual factors known as "transfer conditions"; for example, individual differences, ability, motivation, and whether the context or culture is supportive. In place of more traditional training evaluation, there is growing interest in "logic models" which have been used to evaluate complex behavioural interventions in healthcare by identifying "mechanisms of impact" such as mediators and unanticipated pathways or consequences (Moore et al., 2014).

In accordance with STS theory, logic or systems models provide a holistic and contextualised evaluation of training (Waterson, 2015; Wilson, 2014). Rather than a universal formula, these models are based on a range of subjective views about the intervention and information about any outside influences which could confound its effectiveness (The Scottish Government, 2015). To measure whether EPIC has affected workers' attitudes to risk, changed their 
behaviours, and ultimately reduced the number of incidents on the project is an impossible task; however, logic models have the potential to explain the effect this training is having (both intentional and coincidental) validating its quality and impact. In line with this, our research takes a holistic and contextualised approach to evaluation. It draws on participants' reactions, learning, and behaviour change, as well as considering how the training has been designed, mobilised, reinforced (Tamkin, Yarnall, \& Kerrin, 2002), factors which mediate its impact, any unintended effects, and whether EPIC represents a worthwhile financial investment (Kearns \& Miller, 1997; Phillips \& Holton, 1995).

Although Kirkpatrick's (1959) model has been extensively critiqued and amended in the 60 years since its publication, Kirkpatrick's hierarchy continues to make a valuable and widespread contribution to this field (Bates, 2004). With the present research, it provides a coherent framework against which to structure the evaluation of EPIC.

The following sections discuss the findings from our analysis and make suggestions for how best to implement actor-based training effectively.

\section{Findings}

\subsection{Tideway's aspirations}

One of the advantages of in-depth longitudinal research is that it allows researchers to track how an initiative or intervention evolves over time. Table 1 shows how the intentions behind EPIC were articulated at an early concept stage (in 2013) and then during the design and tender process (in 2015). Knowing these aspirations and objectives is useful because they provide us with a basis against which to evaluate EPIC.

When mapped against Kirkpatrick's (1959) framework it is clear that the early aspirations for EPIC were focused on reactions and first impressions of the project, rather than specific learning objectives. However, at the design stage, the emphasis was very much on learning soft-skills, including challenging, influencing, negotiating, and delivering difficult messages. At neither stage was there much emphasis on behaviour change or measurable results as 
defined by Kirkpatrick - such as presumably the desire to reduce accidents. In the sections below we explore the impact EPIC had at each of the four levels, based on the insights from our evaluation. Following the main data collection for this research we were made aware of an initial proposal from ATT outlining their concept for the induction which they claim is "more complex and nuanced than described in this study". However, ATT's initial proposal was not included in this evaluation as it was not adopted in entirety by Tideway. 
Table 1: Early aspirations and design outcomes for EPIC (mapped against Kirkpatrick's (1959) framework)

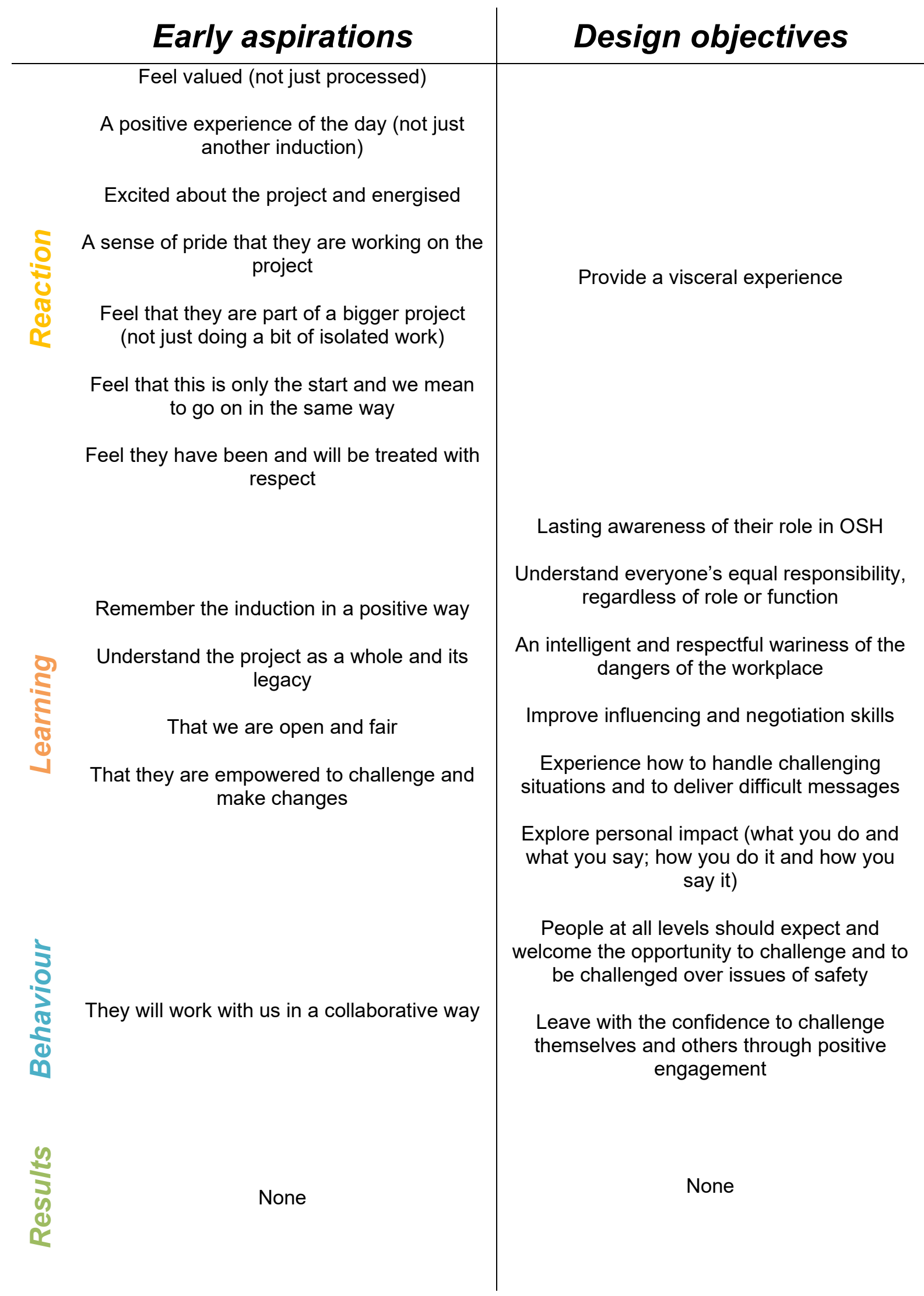




\subsection{Training design}

EPIC is a full-day event in which actors engage delegates in a 'real life' scenario involving a fatal incident on a construction site. Participants have an opportunity to discuss and influence the outcomes of the scenario being acted out in front of them in a purpose-built facility. This is illustrated by the photographs in Figure 3 which show the auditorium for the immersive theatre performance, participants interacting with the actors, workshop activities, and involvement of senior leadership.

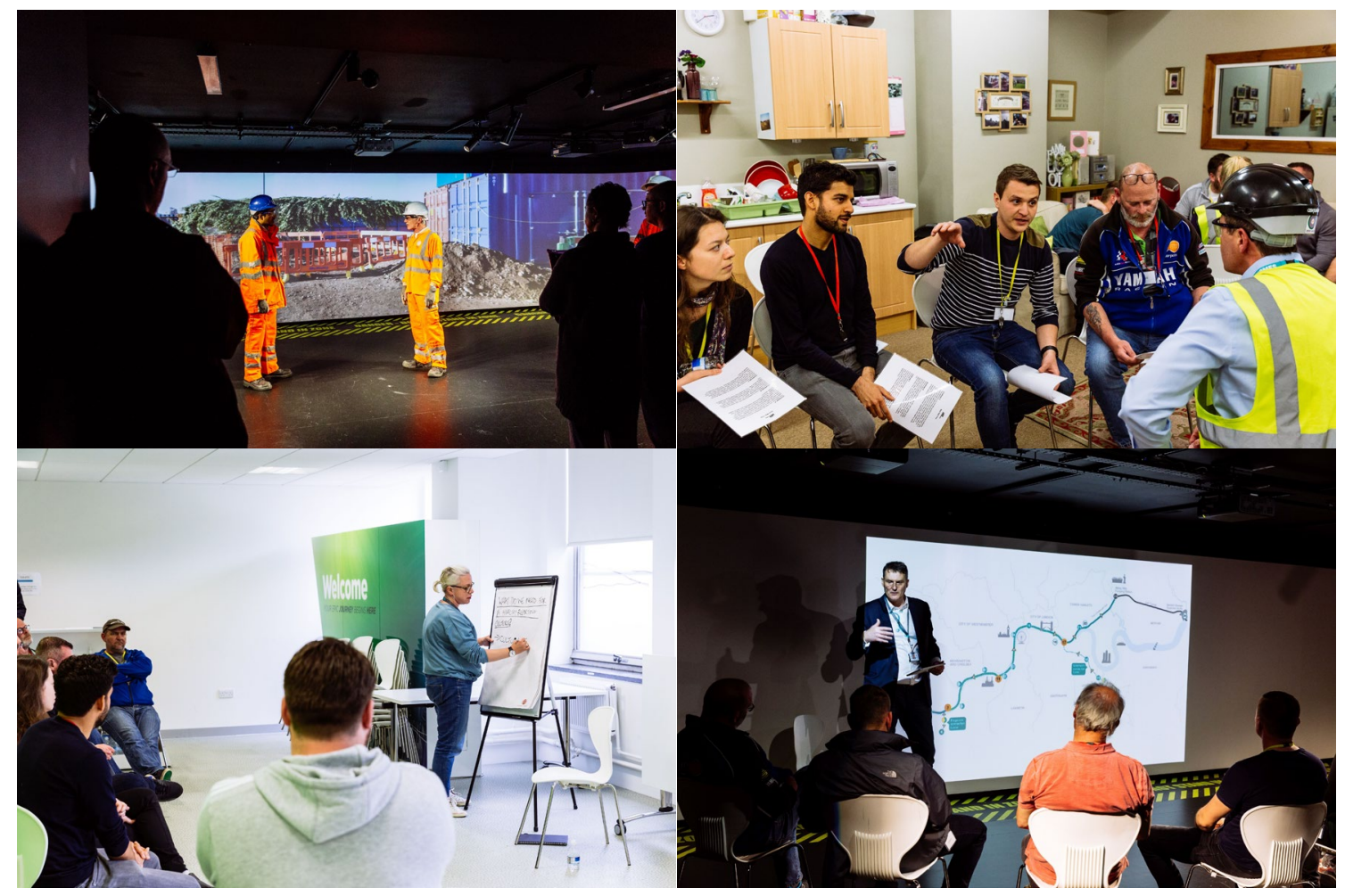

Figure 3: Photographs of the venue and activities at EPIC

One of the aims of EPIC was to provide a 'visceral experience' and for many attendees this was certainly the case. One attendee, writing in an industry newsletter, described how:

"After half a minute's hammering from the breaker there is a flash from the ground and the young operative is engulfed in flames and falls to the concrete thrashing. Over the next hour 
I am taken through $\mathrm{HSE}^{2}$ witness interviews, a company boardroom, a site office and end up in a bedsit being asked by a young woman if her father was screaming when he died."

(Wustemann, 2015)

ATT explain that "what makes EPIC different (and immersive) is the use of site-specific, multimedia, promenade theatre to tell a story. This has more in common with emerging trends in contemporary British Theatre than with the world of corporate training. This unlikely blending of two very different industries to explore behaviour and to influence culture in construction could well be an area for further research".

The emotional impact of the immersive theatre performance is followed up by a facilitated discussion, reflecting collectively on the accident's causes and consequences. Participants then engage in a series of interactive activities designed to help people to be more confident at challenging unsafe behaviours on site. An interviewee described being "Blown away by EPIC, I thought it was a fantastic way to engage absolutely everyone at the start of the project ... Immerse them in a situation and then get them to replay it through and do it one on one."

With a few exceptions, everyone who works on the project must attend EPIC, whatever their role and the duration of their work on the project. At the time of writing this paper in March 2019, more than 14,000 people had attended EPIC.

\subsection{Training evaluation}

\subsubsection{Reaction}

Table 2 provides a summary of the positive and negative reactions to EPIC that we captured through our evaluation. Our evaluation suggests that EPIC has been very well received by many people who attended it. For instance, $79 \%$ of the respondents to our onboarding survey agreed that EPIC was 'excellent', $87 \%$ agreed that it was better than the inductions they had

\footnotetext{
${ }^{2}$ Health and Safety Executive, a UK government agency responsible for regulating and enforcing health and safety in the workplace
} 
experienced on other projects and $72 \%$ agreed that it made them feel part of Tideway (Table 2 and Table 3).

These positive perceptions were also reflected in peoples' responses in the interviews, focus groups and exit surveys. For instance, during the focus groups one worker commented that:

"Yeah, I thought it was really good- it was actually when like other colleagues from [another megaproject] were coming over here, I was really excited for them, like I was like "I can't wait 'til you do it!"”

Table 2: Summary of attendees' responses about reactions from the 2016 exit survey $(n=530)$

\begin{tabular}{lccccc|cc}
\hline Question & $\begin{array}{c}\text { I } \\
\text { strongly } \\
\text { agree }\end{array}$ & I agree & $\begin{array}{c}\text { I'm not } \\
\text { sure }\end{array}$ & $\begin{array}{c}\text { I } \\
\text { disagree }\end{array}$ & $\begin{array}{c}\text { I } \\
\text { strongly } \\
\text { disagree }\end{array}$ & $\begin{array}{c}\text { Total } \\
\text { agree }\end{array}$ & $\begin{array}{c}\text { Total } \\
\text { disagree }\end{array}$ \\
\hline EPIC was well organised & $59 \%$ & $38 \%$ & $3 \%$ & $0 \%$ & $0 \%$ & $97 \%$ & $0 \%$ \\
\hline $\begin{array}{l}\text { EPIC was better than } \\
\text { inductions on other } \\
\text { projects }\end{array}$ & $69 \%$ & $19 \%$ & $11 \%$ & $2 \%$ & $0 \%$ & $87 \%$ & $2 \%$ \\
\hline $\begin{array}{l}\text { I didn't know what EPIC } \\
\text { was about before I went }\end{array}$ & $34 \%$ & $45 \%$ & $5 \%$ & $14 \%$ & $3 \%$ & $78 \%$ & $17 \%$ \\
\hline $\begin{array}{l}\text { EPIC made me feel part } \\
\text { of Tideway }\end{array}$ & $25 \%$ & $47 \%$ & $19 \%$ & $8 \%$ & $1 \%$ & $72 \%$ & $9 \%$ \\
\hline EPIC was surprising & $54 \%$ & $38 \%$ & $6 \%$ & $2 \%$ & $0 \%$ & $92 \%$ & $2 \%$ \\
\hline EPIC was a waste of time & $1 \%$ & $1 \%$ & $4 \%$ & $21 \%$ & $73 \%$ & $3 \%$ & $93 \%$ \\
\hline
\end{tabular}

Table 3: Summary of attendees' responses about reactions from the 2018 exit survey $(n=2927)$

\begin{tabular}{lccccc|cc}
\hline Question & $\begin{array}{c}\text { Strongly } \\
\text { Agree }\end{array}$ & Agree & Neutral & Disagree & $\begin{array}{c}\text { Strongly } \\
\text { Disagree }\end{array}$ & $\begin{array}{c}\text { Total } \\
\text { agree }\end{array}$ & $\begin{array}{c}\text { Total } \\
\text { disagree }\end{array}$ \\
\hline $\begin{array}{l}\text { The style of the workshop } \\
\text { was effective }\end{array}$ & $75 \%$ & $22 \%$ & $2 \%$ & $0 \%$ & $0 \%$ & $97 \%$ & $1 \%$ \\
$\begin{array}{l}\text { The facilitators and actors } \\
\text { responded to questions } \\
\text { effectively }\end{array}$ & $81 \%$ & $18 \%$ & $1 \%$ & $0 \%$ & $0 \%$ & $98 \%$ & $1 \%$ \\
\hline $\begin{array}{l}\text { We were encouraged to } \\
\text { participate during EPIC }\end{array}$ & $77 \%$ & $20 \%$ & $2 \%$ & $0 \%$ & $0 \%$ & $98 \%$ & $1 \%$ \\
\hline
\end{tabular}

Such responses are important because part of the original intent behind EPIC was to create a positive experience for people starting work on the project. In an industry that has a reputation for traditionally not valuing its workers, EPIC was seen as a way of making people feel valued and respected - rather than just being processed - and of creating a sense of 
pride and excitement about working on the project. It was also a way of making the project feel 'different'. The word 'different' was used frequently when people talked about EPIC in interviews and workshops. For instance,

"a lot of the guys won't have come across something like EPIC before ... to take all those people out of work and put them in for a whole day doing something pretty much where you're always talking about safety all the time, is quite new, it is quite different."

Although respondents cited examples of where they had seen actors used before in one-off $\mathrm{OSH}$ training, there was an acknowledgement that EPIC's immersive experience was a step beyond this and represented a significant commitment and investment in time and resources by Tideway. EPIC was described as 'high quality' on a number of occasions during the interviews.

When we asked people what they liked about EPIC, they tended to use words such as 'thought-provoking' 'interactive', 'engaging', 'immersive' and 'emotional' - words that are not usually used to describe $\mathrm{OSH}$ inductions. One respondent commented on how:

"It created an interactive experience that enabled you to immerse yourself into the story that was being told. This is a great way of engaging your audience as opposed to a conference style "pep talk"'.

Creating a believable experience and immersing people in the day was seen to be critical to over-coming peoples' cynicism and getting peoples' 'buy-in', particularly from front-line construction workers who have been through numerous site inductions and may be sceptical about the idea of spending a full day talking about $\mathrm{OSH}$. As participant observers, members of the research team saw examples of attendees who started sceptically but eventually joinedin with the day. People talked about how EPIC was 'hard-hitting', 'emotional' and 'surprising'. Such comments are understandable, given that the scenario that is acted out at EPIC is designed to convey the impact that a fatality has on the people involved. For instance, after 
the fatality one attendee is chosen at random to play the role of a witness in a mock interview with a Health \& Safety Executive (HSE) investigator, which fellow attendees observe. Attendees are also taken into an apartment where they meet the victim's daughter and see photos of his family.

These scenes are particularly effective because most people were not expecting them: in the HSE interview scene the witness was asked challenging questions about what they recalled about the accident on site (which they had just observed), a situation that seemed to jolt the audience into paying attention (because "the person being interviewed could have been me"). One of the positive aspects of EPIC was that people who had already attended the day chose not to spoil the surprise for colleagues who had not yet attended.

Whilst $97 \%$ of attendees completing the exit survey in 2018 found the style of EPIC to be effective (Table 3), not everyone shared this view. Some people suggested that EPIC was simply repackaging the same messages that you hear in other $\mathrm{OSH}$ inductions, while others found the acting 'unrealistic' and expressed a preference to hear real people and their firsthand experiences of being involved in accidents. Some attendees reported feeling uncomfortable, either because they found the scenes being acted out to be too emotive or stressful, or because they were being taken out of their 'comfort zone' by being asked to take part in interactive role play with actors and other attendees. One construction worker argued that "We don't want to talk to people, you know what I mean? We shouldn't have to." ATT have stated that "during the immersive performance section, the ushers are trained to notice if any participants are becoming distressed, and offer them the option of using the 'quiet room"'

Another criticism of EPIC - and one shared by people who otherwise talked very positively about the day - was that it was too long, which meant participants tended to lose interest as the afternoon progressed. This was particularly the case for those who had travelled a long distance to attend. Participants' positive and negative reactions to EPIC, gathered from the interviews, focus groups, and exit feedback, are summarised in Table 4. 
Table 4: Summary of positive and negative reactions to EPIC

\begin{tabular}{cc}
\hline Positive reactions & Negative reactions \\
$\begin{array}{c}\text { Realistic and believable } \\
\text { (so people buy-into it) } \\
\text { Novel/different }\end{array}$ & $\begin{array}{c}\text { The day was too long for most people } \\
\text { (people lost interest) }\end{array}$ \\
$\begin{array}{c}\text { Emotive/hard-hitting (which helps to drive } \\
\text { the message home) } \\
\text { Immersive }\end{array}$ & $\begin{array}{c}\text { Not all of the content was relevant to } \\
\text { everyone (one approach for all) } \\
\text { Some people felt uncomfortable } \\
\text { Element of surprise } \\
\text { Sign of commitment } \\
\text { Some people found the acting to be } \\
\text { unrealistic }\end{array}$ \\
& $\begin{array}{c}\text { Repacking the same messages as other } \\
\text { OSH inductions }\end{array}$ \\
& $\begin{array}{c}\text { Single location meant many people had to } \\
\text { travel a long distance to attend }\end{array}$ \\
\hline
\end{tabular}

\subsubsection{Learning}

The objectives behind EPIC (Table 1) put a significant emphasis on learning and this was reflected in the design of the day: the scenario being acted out at EPIC was designed to impress upon people their responsibility for $\mathrm{OSH}$ on site; the afternoon's activities were designed to provide attendees with practical skills and tactics for challenging unsafe behaviours on site and for them to leave with the confidence to challenge others through positive engagement. The focus on learning was also reflected in the messages conveyed at EPIC, which were about making sure everyone gets home at the end of each day, looking after each other, not taking risks and shortcuts, and the repercussions of getting hurt.

There is evidence from our research to suggest that many attendees did learn something at EPIC, based on their self-reported feedback. For instance, $94 \%$ of respondents to the 2018 exit survey (Table 6) agreed that "Today has made me more confident in challenging unsafe behaviour" and $95 \%$ of respondents agreed that "I will apply what I learned today." Similarly, in the 2016 onboarding survey: $72 \%$ of respondents agreed that EPIC had improved their understanding of Tideway; $85 \%$ agreed that it had improved understanding of safety; $78 \%$ agreed that it had improved their understanding of health issues; and 78 percent of respondents agreed that it made them more confident about stopping unsafe work (Table 5 and Table 6). 
Table 5 Summary of attendees' responses about learning from the 2016 exit survey $(n=530)$

\begin{tabular}{cccccc|cc}
\hline Question & $\begin{array}{c}\text { I strongly } \\
\text { agree }\end{array}$ & I agree & $\begin{array}{c}\text { I'm not } \\
\text { sure }\end{array}$ & $\begin{array}{c}\text { I } \\
\text { disagree }\end{array}$ & $\begin{array}{c}\text { I strongly } \\
\text { disagree }\end{array}$ & $\begin{array}{c}\text { Total } \\
\text { agree }\end{array}$ & $\begin{array}{c}\text { Total } \\
\text { disagree }\end{array}$ \\
\hline $\begin{array}{c}\text { EPIC improved my } \\
\text { understanding of Tideway }\end{array}$ & $26 \%$ & $46 \%$ & $14 \%$ & $13 \%$ & $1 \%$ & $72 \%$ & $14 \%$ \\
\hline $\begin{array}{c}\text { EPIC improved my } \\
\text { understanding of health } \\
\text { issues at work }\end{array}$ & $32 \%$ & $38 \%$ & $16 \%$ & $12 \%$ & $1 \%$ & $71 \%$ & $13 \%$ \\
\hline $\begin{array}{c}\text { EPIC improved my } \\
\text { understanding of safety at } \\
\text { work }\end{array}$ & $42 \%$ & $43 \%$ & $7 \%$ & $6 \%$ & $1 \%$ & $85 \%$ & $8 \%$ \\
\hline $\begin{array}{c}\text { EPIC changed the way I } \\
\text { work }\end{array}$ & $16 \%$ & $38 \%$ & $29 \%$ & $15 \%$ & $2 \%$ & $54 \%$ & $17 \%$ \\
\hline $\begin{array}{c}\text { EPIC made me more } \\
\text { confident about stopping } \\
\text { unsafe work }\end{array}$ & $31 \%$ & $47 \%$ & $13 \%$ & $7 \%$ & $2 \%$ & $78 \%$ & $9 \%$ \\
\hline $\begin{array}{c}\text { I understood everything at } \\
\text { EPIC }\end{array}$ & $38 \%$ & $57 \%$ & $3 \%$ & $2 \%$ & $0 \%$ & $95 \%$ & $2 \%$ \\
\hline
\end{tabular}

Table 6 Summary of attendees' responses about learning from the 2018 exit survey $(\mathrm{n}=2927)$

\begin{tabular}{cccccc|cc}
\hline Question & $\begin{array}{c}\text { Strongly } \\
\text { Agree }\end{array}$ & Agree & Neutral & Disagree & $\begin{array}{c}\text { Strongly } \\
\text { Disagree }\end{array}$ & $\begin{array}{c}\text { Total } \\
\text { agree }\end{array}$ & $\begin{array}{c}\text { Total } \\
\text { disagree }\end{array}$ \\
\hline $\begin{array}{c}\text { Today has made me more } \\
\text { confident in challenging } \\
\text { unsafe behaviour }\end{array}$ & $64 \%$ & $30 \%$ & $4 \%$ & $1 \%$ & $1 \%$ & $94 \%$ & $2 \%$ \\
\hline $\begin{array}{c}\text { The content of today was } \\
\text { relevant to me }\end{array}$ & $55 \%$ & $35 \%$ & $8 \%$ & $2 \%$ & $1 \%$ & $90 \%$ & $3 \%$ \\
\hline $\begin{array}{c}\text { I will apply what I learned } \\
\text { today at work }\end{array}$ & $60 \%$ & $34 \%$ & $4 \%$ & $1 \%$ & $0 \%$ & $95 \%$ & $1 \%$ \\
\hline $\begin{array}{c}\text { Everyone, regardless of } \\
\text { role or function is }\end{array}$ & $94 \%$ & $5 \%$ & $0 \%$ & $0 \%$ & $0 \%$ & $99 \%$ & $0 \%$ \\
$\begin{array}{c}\text { responsible for health and } \\
\text { safety }\end{array}$ & & $35 \%$ & $8 \%$ & $1 \%$ & $0 \%$ & $91 \%$ & $1 \%$ \\
\hline $\begin{array}{c}\text { When it comes to safety, I } \\
\text { see myself as a leader }\end{array}$ & $56 \%$ & & & & & \\
\hline
\end{tabular}

These results were also reflected in the comments people made during the interviews and focus groups, where they explained how EPIC had 'made them think', 'opened their eyes', and 'got the message home':

"I had never experienced anything like it before. I loved the fact that it was interactive and emotional. It actually meant something. I came away feeling as though I could challenge a construction site worker should I feel the need to." 
"I have completed numerous health and safety courses with the majority being death by PowerPoint. EPIC is immersive and inclusive throughout and because of this the content is easily retained by participants. It is very thought provoking for all the right reasons."

Some respondents felt that the activities ${ }^{3}$ designed to teach behavioural theory were more relevant to supervisors and managers and less relevant to front-line operatives, because "you're trying to educate people about the way their mind works and everything in an afternoon and we're not psychologists". However, despite this, $90 \%$ of attendees who responded to the exit survey agreed that the content of the day was relevant to them (Table 6).

EPIC was also described as 'memorable' on a number of occasions during the interviews and focus groups. For instance, one interviewee explained how:

"It's very memorable and I think it's good because I think people go there expecting to be sat in front of a presentation all day. So, I think even just doing something different than that is a way of engaging them and remembering it."

However, while people may remember the day itself as a positive experience, doubts were raised about whether people would remember what they had learned once they had started work on site:

"It's easy to forget, that's the thing. Because once you're out there and you're back in the real world and you're working away."

"It's like manual handling training. For the first day or two afterwards you will do it right. After that you'll go back into your old ways. The only way you're going to change that is by continuous training or, instilling each other to challenge yourself on it."

\footnotetext{
${ }^{3}$ The activities were about how to challenge unsafe behaviours ("The ladder of challenge" and "do's and don'ts"), transactional analysis ("I'm OK - You're OK"), providing feedback ("Behaviour, Impact, Feelings, Future"), the importance of asking open questions, and increasing your presence ("Status Circles").
} 
"EPIC was wonderful, but I asked the question at it, "What are we going do to keep this alive?" Because if you don't remind people the photograph of the lady, you know, the girl whose dad died or whatever, it goes. It does go. I know it does."

Such doubts underlined the importance of reinforcing the messages conveyed at EPIC and that is something that Tideway and their principal contractors have looked to do, for instance through OSH stand-downs (where all work is paused on site for a few hours to focus on a particular issue). The impact of these reinforcing activities is beyond the scope of this paper ${ }^{4}$, but evidence from our interviews suggests that their effectiveness has been mixed and that more could have been done to reinforce the messages from EPIC during site inductions. Interestingly, actors have been used at some stand downs, although they have not always been as well received. For instance, one site worker explained how

"Actors were good on the first one on the EPIC because it was something new, something fresh. But when you - you can tell when there's an actor and they'd prefer to be a part of the lads on the ground but they can't be, because they haven't got the lingo, they haven't got the swagger, they haven't got the culture, they haven't got all that side of things that proves they're one of the guys or girls on the ground"

There are clearly challenges with reinforcing the messages at EPIC, not least the cost and resources required to do so on a regular basis across a large workforce tasked with delivering a megaproject. The turnover of workers is also a barrier, in that some people will only be working on the project for a short period of time to carry out a particular activity - in these cases the opportunity to reinforce the messages from EPIC (and thereby create a positive legacy beyond the project) may be limited.

${ }^{4}$ ATT have stated that their initial proposal "included embedding and refresher elements" 


\subsubsection{Behaviour}

Behaviour change was one of the most common themes discussed in the interview data on EPIC. Although behaviour change was not explicit in the early aspirations and design objectives for EPIC (Table 1), it was arguably the underpinning rationale for an event which provides people with the confidence to challenge themselves and others through positive engagement. During the interviews people talked about how EPIC 'legitimises different conversations', is about 'setting expectations' and 'sets the tone for doing things differently on the project'.

There was anecdotal evidence, from the interviews and focus groups, of a greater willingness for people to challenge and discuss issues on site. For instance,

“Quite often people will challenge. We've had issues or incidents where people have raised things up to management in a way that maybe on previous projects, they wouldn't have felt safe to do so. You know, they feel it could affect their job if they speak up about a supervisor for example or something like that and people have done so here. And I think we do believe that we've given them the message that it's safe to come and talk to management about safety and there have been examples of that..."

However, people also acknowledged the difficulty of making the link between EPIC and these types of behaviours. As one manager explained "It's always difficult because you don't turn around and say, 'Oh did you come and tell us that because you did EPIC?'”

During the focus groups, front-line workers were asked if what they had learnt at EPIC had made them do them do things differently, but people tended not to make a connection between the two. For example, the following exchange between an EPIC attendee (A) and a researcher (R) points to the difficulties of establishing whether EPIC has changed peoples' behaviours:

A: That was the most impressive induction l've ever had in my life. 
R: And you've had a few (laughs). Has it changed anything that you do, the way you work?

A: The way I think I would say. Not the way I work, because I'm trying to work extremely safely. But just the way I think.

$R:$ Any examples of that?

A: Just let's say think twice before you do something. Or if you're not sure, simple, ask.

There are many confounding variables, including: peoples' attitudes, personalities, capabilities; those of their supervisor; and the culture on site.

Other respondents were much more sceptical about the impact that EPIC has had on peoples' behaviours. One interviewee explained how "The guys, I know guys in the afternoon who'll think, what the $f^{\star *} k$, you can either challenge somebody or you can't ... no card with a ladder [of challenge ${ }^{5}$ ] is going to make me do things different."

The culture on site will ultimately influence what people do and how they do it. A recurring theme in the interviews was that supervisors and managers have the greatest influence on how people behave on site and that will always overshadow the impact of one-off inductions such as EPIC, regardless of how good they are:

"It has to be led from the managers and the bosses which is the corporate spiel you give, but really it gets left to the black hats and that on site, the supervisors. They're the guys and girls that will make the difference, they're the ones that instil a good culture. Because a supervisor who supports, respects and understands the manager and voices and is respected by his manager, he'll work well for the guys and the guys will respect him as well and it will work."

\footnotetext{
${ }^{5}$ One of the tools taught at EPIC.
} 
"Of course, like any sort of training however good it is it's not a magic bullet. So, if people then arrive on site and the supervision isn't tight the culture can change and people can revert back to old behaviours or one people who's a very strong character can influence a whole bunch of people. ...it's a very good starting point as, "Right, this is going to be different." But you've then got to do a hell of a lot to keep that going and see it through. It's still good but it's not all you need to do."

Arguments such as these suggest that emphasis is needed on developing leaders who are able to empower workers and develop a positive culture on site. Indeed, a number of interviewees argued that the money invested EPIC would have been better spent on training:

"I enjoyed EPIC but it's a one-day event, it's forgotten it doesn't have a long-lasting effect, I don't think it's going to have. So, are we spending money where we don't need to spend money? If we had a training centre and we spent that equivalent same money...it would actually deliver a little bit more. You want to up-skill workers, up-skilling the workers is the most important thing I think anyway"

Making a link between EPIC and behaviour change is clearly challenging, however, for some respondents the lack of behaviour change demonstrated EPIC's ineffectiveness as its message was not fully enforced on site. For instance,

"EPIC was good, but you know, it's a shame it hasn't really been implemented on site- it has to a certain degree, but there is- there is certain levels of- I don't know, management, who you can't really- you can't really talk to them because they think they know best."

“No, no, well it's not a matter of challenging, it's just there are- it's certain people's attitude towards- towards the workers is them and us, there's a barrier- well I just ignore them, I mean OK he's- those people are in the decision, they're in the decision for a reason [because] they've got the experience, they're obviously 
working for the project, but they- they need to listen to us as well. They need to listen to us."

"Has it changed behaviour? I would say probably not. I've got no evidence of that other than still having people making the wrong decisions ... But [EPIC is] all about a series of wrong decisions; little wrong decisions. Someone gets killed. And people are still making the little wrong decisions, so the evidence would be maybe not."

Such comments are also interesting because they describe behaviours that are highlighted and challenged at EPIC, which suggests that people either fail to take onboard the messages from EPIC or, more likely, they abandon them once faced with the reality of working on site.

\subsubsection{Results}

The early aspirations and design objectives for EPIC (Table 1) did not refer to any specific results, such as a reduction in accidents or other OSH outcomes. As with behaviour change, one might assume that these were implicit in the thinking behind EPIC - that is to say, by raising peoples' awareness and giving them the confidence to challenge unsafe behaviours, EPIC would help to improve practices on site. However, even if this was the case, it would be very difficult to establish a link between EPIC and OSH outcomes because there are so many confounding factors.

Perhaps the most obvious 'result' of EPIC is that it has 'raised the bar' for the construction industry. EPIC demonstrates that project inductions can be done differently and improve on the typical experience for most construction workers. Yet the things that make EPIC compelling also make it expensive: the custom designed facility and set; the actors; and paying workers to attend for a whole day. One interviewee suggested that the costs associated with EPIC were the reason why EPIC had not been adopted on another megaproject in the UK, although the concept has recently been adopted by another major contractor. Nevertheless, the cost was deemed worthwhile by senior OSH management: 
"whilst there is no doubt it has been a massive investment, the impact that it has had on the industry in terms of the way it makes them think, the expectation for the future and the kind of demonstration of commitment to health and safety. I think is second to none, so I think it has been worth it ultimately."

At the time of writing this paper, arguably the most noticeable 'result' of EPIC was an unintended one: raising the expectations of workers to a level that could not always be achieved on site. For instance, during the senior management talk at EPIC attendees were informed that "Our sites will be the safest you have ever seen" and "Our canteens and toilets/washrooms are going to be better than anything you have ever seen - on or off site!". Such promises proved difficult to achieve during the early mobilisation of the project, when sites were being set up and enabling works were being carried out.

"We haven't got a lovely welfare although we're telling the guys at EPIC that that's what is going to happen... So I think some of our people here who've come to this site to work are a little bit disappointed that they were told these great things about Tideway and when they get here, it's not really there yet."

Concern about over-promising at EPIC - and the 'disappointment', 'embarrassment' and subsequent negative impact this can have on peoples' trust - was a recurring theme in our interviews. For instance:

"Well yeah, I think there were a lot of promises made at EPIC and where we are failing on that is that we haven't delivered yet. So, we are getting pushed back, so that trust, there is great trumpeting at EPIC about you are going to get the best PPE and you are going to have the greatest welfare... well you are no better than anyone else. You are saying that you are, so we have already lost a bit of that trust which is a shame." 
"So, it sets a false expectation. They come here and straightaway we're already on a back foot because they're pissed off because they haven't got what we said they were going to get."

As well as over-promising on worker welfare, EPIC also created high expectations in other ways: an emphasis on the project being 'different' from other projects created a disconnect between what workers expected and what they experienced on site. For instance,

"And in EPIC training we had "There's no pressure, there's no this and that", the person that does the EPIC really needs to come on site and have a look, and see what actually really does happen! At the end of the day most sites have got the same sort of thing. They're all under pressure."

Overall, there was a feeling that the messages being conveyed at EPIC needed to be attenuated to match the reality of what could be delivered on site.

\section{Discussion}

Our evaluation revealed a mixed picture of the impact that EPIC has had on the people who attended it. The majority of attendees who provided feedback on EPIC reported a positive reaction to the day and claimed to have learned something from attending. EPIC was seen to be different and much more engaging than the type of induction workers normally received on construction projects. The response to this experiential and personalised approach to learning has been positive overall, although some participants found it uncomfortable, confusing, embarrassing, or patronising. It is important to consider carefully the amount of behavioural theory introduced to participants: This can be off-putting and was perceived as irrelevant by some frontline workers. Behavioural theory is arguably most effective when it is less overt and more embedded in the scenario being acted out. Despite responses to the exit survey indicating EPIC had changed the way attendees would work (Table 5 and Table 6), this was not verified by examples of changed behaviour when this was followed up in interviews and focus groups. This is perhaps unsurprising given that these were never part of the stated 
aspirations and outcomes of EPIC. However, it could be argued that they are implicit in what EPIC is about.

Evaluating behaviour-change or training programmes is problematic because "in the chaotic real world there are hundreds of variables which can affect people's attitudes, motivations and behaviour" (The Scottish Government, 2015, p. 3). A robust assessment of the effect of the training on behaviour would require repeated measures or a randomised trial with a control group as a comparator; this is rarely feasible and poses an ethical issue where, as in the case of EPIC, the training is safety-critical.

Based on evidence gathered for this evaluation, a logic model (Figure 4) has been developed to illustrate the mechanisms and outputs of EPIC in relation to four of Tideway's objectives (Table 1). The inputs are the aspects of the event designed to achieve these objectives. Many of these have resulted in positive outputs. Like most safety training programmes, EPIC emphasises an individuals' responsibility to prevent accidents and supports challenging unsafe behaviour, but also demonstrates Tideway's commitment to prioritise and invest in safety, respect and value workers, and inspire pride in the project. Rather than focussing on compliance, EPIC introduces practical techniques in a way which builds community and stimulates discussion on risk. However, there are also many factors which have reduced the effectiveness of the training.

These confounding variables have been categorised in accordance with the Four Levels: "Reaction" includes factors which prevent inductees fully engaging on the day or mean they do not have a positive experience; "Learning" factors prevent them taking on board the concepts or messages; and "Behaviour" factors prevent the inductees implementing their learning from EPIC on site. At each of these levels the initial positive impressions are attenuated. 


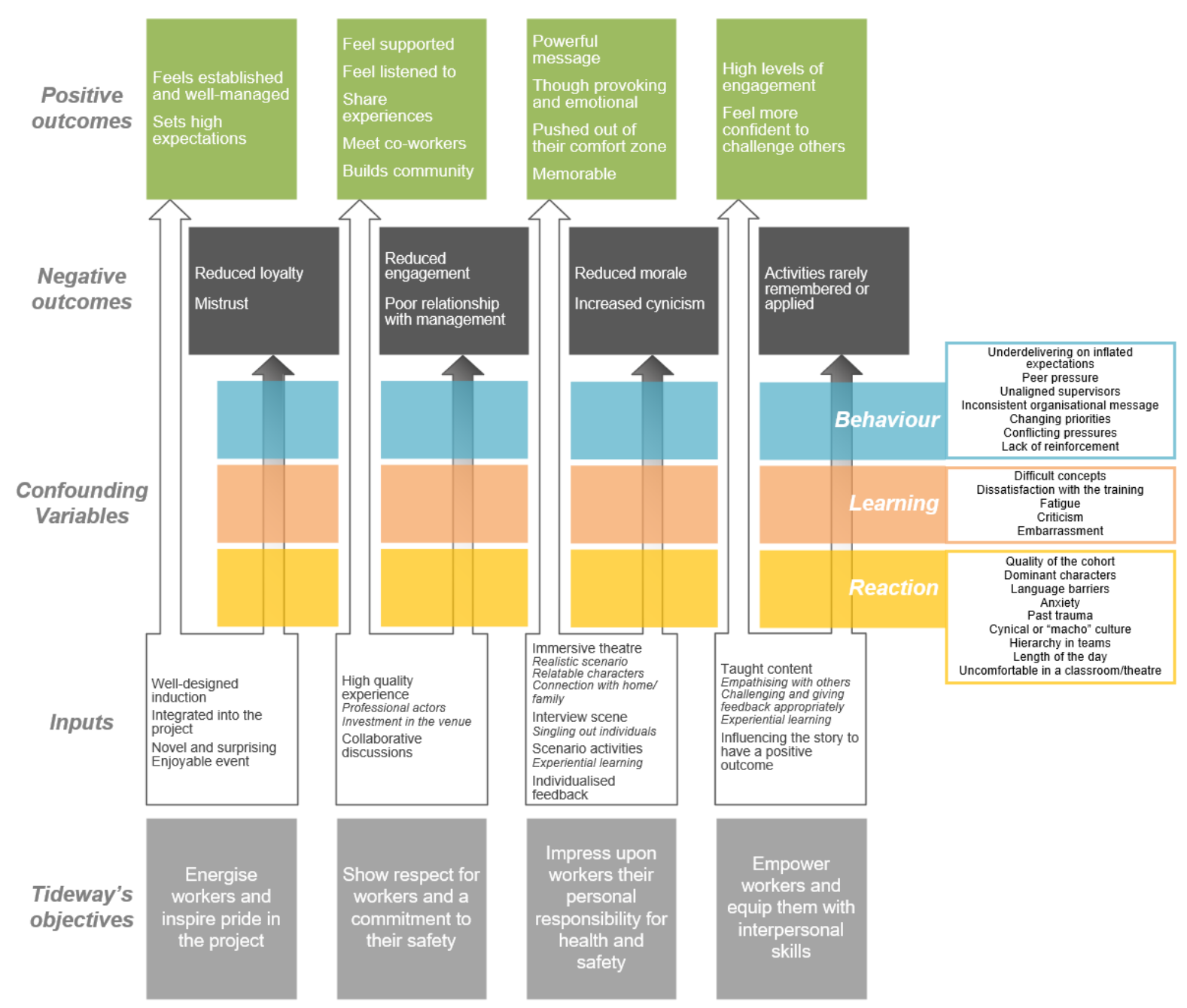

Figure 4: A logic model illustrating the effects of EPIC

Not only do these variables reduce training effectiveness, they are also responsible for unintended negative outcomes. For instance, EPIC sets high expectations at the start of the project with a unique and quality experience, but in the reality of construction work its messages are undermined by budgetary constraints, tight deadlines and a lack of job security. This can harm trust, morale, and relationships between workers and management. The emphasis on collaboration and engagement at EPIC, which is then not substantiated by some supervisors on the project, only highlights these disappointments and exacerbates complaints. These positive and negative mechanisms are elaborated further below.

The fact that EPIC elicited a positive reaction from attendees was important for a number of reasons. One reason is that, while there is no association between a positive training 
experience and learning effectiveness, research has shown that if attendees have a poor experience this does impact negatively on learning (O'Conner et al., 2002). For instance, de Oliveira et al. (2015, p. 54) explained how "If the student sees the simulation as a joke, reflection becomes meaningless, and learning is no longer anchored in a meaningful experience". Getting participants' buy-in is therefore critical for actor-based training being worthwhile (Nestel et al., 2008).

One way that EPIC achieved participants' buy-in was by providing a realistic experience. This was achieved through the use of professional actors, collaboration with industry experts, and extensive research to ensure the script and characters were as realistic as possible - including the storyline, technical terminology, jargon and accents. Many authors have commented on the importance of realism to ensure the success of actor-based training (Bell et al., 2014; Lexton et al., 2005; Wilson, 2000) because high psychological fidelity allows participants to experience authentic emotions (de Oliveira et al., 2015). Indeed, this reflects the feedback received about EPIC, which attendees described as emotional and hard-hitting. As well as securing participants' buy-in, a sensitive and multidimensional portrayal is important so as not to trivialise the topic of the training or perpetuate negative stereotypes (Lexton et al., 2005).

Whilst "learning through engaging the emotions is an effective tool in changing practice" (Horwath \& Morrison, 1999, p. 156), some attendees at EPIC raised concerns about the emotionally stressful nature of the day. Previous research has shown how "role-play can have a powerful emotional impact and may have a damaging effect on individual participants, perhaps reactivating painful experiences from the past" (Lexton et al., 2005, p. 202). Individuals may react unpredictably or negatively; thus, Lexton et al. (2005) recommended that actors remain alert, sensitive, and responsive, and the means to support and debrief participants must be incorporated into the training design. However, several members of our research team felt this had not been adequately provided for at EPIC, based on their experience as participant-observers. This was seen to be a particularly problematic because 
of the prevalence of construction accidents, ex-military personnel and the sector's "macho" culture.

The key to effective actor-based training is creating a "safe environment" (Bell et al., 2014) where participants feel able to take risks (Lexton et al., 2005). Anxiety can prevent participants fully committing to an actor-based scenario (Finn, 2014), yet Tideway's proposal specifies pushing participants "out of their comfort zone". Actors can adjust the scenario to make it more or less difficult - stretching each participant's ability (Bell et al., 2014; Finn, 2014). However, done poorly, this can be counterproductive if participants feel ridiculed and lose confidence (Lexton et al., 2005). Positive and immediate feedback is key to meaningful learning (de Oliveira et al., 2015). This underlines the importance of EPIC's 'happy ending', where the participants have an opportunity to apply the skills they have learnt to challenge the actors' behaviour and prevent the accident.

When adjusting to a new work environment, surprises or "discrepant events" (p.241) act as a trigger to force people to update their expectations in line with the organisation (Louis, 1980). The surprise and novelty of EPIC aligns with Tideway's ambition to 'raise the bar' - challenging the norms of the industry - but could also compromise the effectiveness of actor-based training - in which participants need to feel safe to experiment. The problem of creating a safe space to learn versus resetting expectations as part of onboarding is an important consideration for how actor-based training should be used in this sector.

Most respondents in our research had a positive reaction to EPIC, however not everyone bought-into it. Some more experienced workers were observed to be slower to engage, echoing Bell's (2014) finding that scepticism about the use of actors in healthcare training increased with experience and seniority. Interestingly, workers at Tideway found actors less realistic in follow-up events conducted on site. Again, this reflects research in healthcare, where Nestel et al. (2008) found that surgeons were more critical of the performance if they knew the anaesthetist was being played by an actor. This suggests the element of surprise is 
important to the impact of EPIC; once workers have been exposed to EPIC they are alert to and more sceptical of the use of actors in future events. This also raises doubts about the longevity of actor-based training for in construction if its success relies significantly on its novelty.

Actor-based training offers a valuable means to develop the interpersonal skills necessary for safety leadership; however, even with the support of simulations, converting theory into practice is a complex process (Lee-Kelley, 2018). Our research suggested that the culture on site - and particularly the attitudes and actions of supervisors and managers - played a key role in socialisation and the resulting behaviours of workers. These factors mediate the effectiveness of EPIC and highlight the difficulty of evaluating training or other safety interventions in the real world.

Table 7 captures the key points of learning that emerged from our evaluation, knowledge of which could be used to inform the design of other immersive, actor-based inductions, both in construction and other sectors. Some of the learning is about what could be done to make these types of inductions successful; other areas of learning are around what to avoid doing when designing and implementing actor-based inductions. One of the key areas of learning is that, while it is important to create a positive learning experience on the day, thought also needs to be given to what happens after the event. This includes: reinforcing messages from the day; considering the impact that this type of induction will have on behaviour change and health and safety outcomes; and thinking about how the impact will be measured.

\section{Table 7: Key learning points from EPIC}

\begin{tabular}{cl|l}
\multicolumn{1}{c|}{ Do } & \multicolumn{1}{c}{ Avoid } \\
\hline Results & $\begin{array}{l}\text { Set clear learning objectives and } \\
\text { include how these will be assessed in } \\
\text { the training design. }\end{array}$ & $\begin{array}{l}\text { Relying only on a questionnaire } \\
\text { capturing reactions. } \\
\text { Evaluating the } \\
\text { effectiveness }\end{array}$ \\
Collect data unobtrusively. & $\begin{array}{l}\text { Setting expectations which cannot be } \\
\text { delivered. }\end{array}$ \\
\hline
\end{tabular}




\begin{tabular}{|c|c|c|}
\hline Behaviour & $\begin{array}{l}\text { Integrate the training into the wider } \\
\text { OSH strategy. }\end{array}$ & \\
\hline $\begin{array}{l}\text { Support for } \\
\text { implementing } \\
\text { training on site }\end{array}$ & $\begin{array}{l}\text { Reinforce its messages and provide } \\
\text { reminders. } \\
\text { Consider the influence of supervisors } \\
\text { and culture on site. }\end{array}$ & $\begin{array}{l}\text { Assuming that one day will change } \\
\text { the way people behave. }\end{array}$ \\
\hline $\begin{array}{l}\text { Learning } \\
\text { Ensuring the } \\
\text { messages are } \\
\text { taken onboard }\end{array}$ & $\begin{array}{l}\text { Select scenarios and characters most } \\
\text { people can relate to. } \\
\text { Encourage people to reflect on their } \\
\text { own experiences. } \\
\text { Encourage people to share } \\
\text { experiences and learn from their } \\
\text { peers. } \\
\text { Provide immediate and positive } \\
\text { feedback. }\end{array}$ & $\begin{array}{l}\text { Teaching complex or abstract } \\
\text { concepts. } \\
\text { Making the day too long or intense, } \\
\text { especially as people may commute } \\
\text { long distances. }\end{array}$ \\
\hline $\begin{array}{l}\text { Reaction } \\
\text { Engagement } \\
\text { and a positive } \\
\text { experience on } \\
\text { the day }\end{array}$ & $\begin{array}{l}\text { Research scenarios and recruit actors } \\
\text { who can make the experience as } \\
\text { authentic as possible. } \\
\text { Consider how the training will be } \\
\text { experienced by someone with English } \\
\text { as an additional language. } \\
\text { Create a "safe space" where people } \\
\text { can fully engage - some workers } \\
\text { might be uncomfortable in a } \\
\text { classroom or theatre. }\end{array}$ & $\begin{array}{l}\text { Triggering memories of traumatic } \\
\text { experiences - provide a warning or } \\
\text { opt-out. } \\
\text { Excluding anyone - facilitators should } \\
\text { ensure everyone has an opportunity } \\
\text { to contribute. }\end{array}$ \\
\hline
\end{tabular}

\section{Limitations}

Establishing the longer-term impact of EPIC on attendees has proved difficult. Behaviour change and results were not explicitly part of the early aspirations and design objectives for EPIC, despite being an implicit part of what the day is about. Although some people reported having learnt something at EPIC; talked about how it had made them think differently; or said it had given them the confidence to challenge unsafe behaviours, it is difficult to ascertain whether this has actually translated into changes in behaviours or improved OSH outcomes not least because there are so many confounding factors at play. Culture, particularly, the attitudes and conduct of supervisors and managers, have the biggest influence on how people behave on site. EPIC can undoubtedly play a role in shaping this culture, but the messages 
conveyed at EPIC need reinforcing on site if they are to have an enduring and meaningful impact. Other $\mathrm{OSH}$ interventions will also play a critical role in influencing how people think and behave.

\section{Conclusions}

The aim of the evaluation was to examine the impact of EPIC from the perspective of participants and other stakeholders, and to consider whether actor-based immersive OSH inductions could be used more widely, in both construction and other sectors. To genuinely engage workers in meaningful conversations about $\mathrm{OSH}$, there is benefit in inductions moving beyond the use of traditional briefings, to provide a more immersive and interactive experience for workers. Actor-based training is employed at EPIC to deliver a powerful message about the consequences of accidents and to emphasise individuals' role in preventing them. However, immersive sessions will not suit everyone. Care needs to be taken to manage the emotional nature of the day, which some people can find stressful.

The novelty of actor-based training, applied as part of an onboarding process, prompts workers to reset their values to align with the ethos of the project. The early aspirations for EPIC were as much about making workers feel valued and creating a sense of common purpose, as they were about raising awareness of $\mathrm{OSH}$ issues. The importance of making people feel appreciated should not be underestimated in an industry that has traditionally been poor at valuing a largely transitory workforce; however, expectations need to be managed so as not to damage trust when these ideals cannot be met. EPIC was launched during the mobilisation of the Tideway project, which in one sense was very positive because it set high expectations for safe working from the outset. However, sites were still being prepared, meaning many of the promises made at EPIC could not be met on site. It is important to manage peoples' expectations or attenuate the messages at an induction such as EPIC, to reflect what is feasible given the stage of the project. 
The use of actors was clearly a distinguishing feature of EPIC and one of the features that made it feel different and novel, along with the purpose-built facility and dedicating an entire day to a project induction. However, the things that make EPIC novel also make it expensive to create and run, thereby restricting the degree to which the concept could be used on other projects, particularly smaller projects with more limited resources. There may be a case for creating an industry-wide version of EPIC, which smaller projects can have access to, however this would need to have a demonstrable return on investment, for instance in terms of improved $\mathrm{OSH}$ outcomes. The lack of evidence about the longer-term impact of EPIC makes it difficult to determine what return on investment EPIC provides when compared with other OSH interventions. Even in a longitudinal study such as this one, practical and ethical considerations meant that it was difficult to determine whether EPIC influenced peoples' behaviour or OSH outcomes.

\section{Acknowledgements}

This work was funded by the Institution of Occupational Safety and Health (IOSH) and Bazalgette Tunnel Ltd. The authors would like to thank the staff at the Tideway project and Active Training Team for allowing us to access and study EPIC.

\section{References}

Alliger, G. M., \& Janak, E. A. (1989). Kirkpatrick's levels of training criteria: thirty years later. Personnel Psychology, 42(2), 331-342.

Anderson, N. R., Cunningham-Snell, N. A. and Haigh, J. (1996). 'Induction training as socialization: Current practice and attitudes to evaluation in British organizations', International Journal of Selection and Assessment, 4(4), 169-183. doi: 10.1111/j.14682389.1996.tb00052.x.

Ashforth, B. E., \& Saks, A. M. (1996). Socialization Tactics: Longitudinal Effects on Newcomer Adjustment. Academy of Management Journal, 39, 149-178 https://doi.org/10.2307/256788

Bates, R. (2004). A critical analysis of evaluation practice: the Kirkpatrick model and the principle of beneficence. Evaluation and Program Planning, 27, 341-347. https://doi.org/10.1016/j.evalprogplan.2004.04.011

Batistič, S., \& Kenda, R. (2018). Toward a model of socializing project team members: An integrative approach. International Journal of Project Management.

https://doi.org/10.1016/j.ijproman.2018.03.003 
Bell, S. K., Pascucci, R., Fancy, K., Coleman, K., Zurakowski, D., and Meyer, E. C. (2014). The educational value of improvisational actors to teach communication and relational skills: Perspectives of interprofessional learners, faculty, and actors. Patient education and counselling, 96(3), 381-388.

Bernthall, P. R. (1995). Evaluation that goes the distance. Training and Development, 49(9), 41-45.

Bushnell, D. S. (1990). Input, process, output: a model for evaluating training. Training and Development Journal, 44(3), 41-43.

Cable, D. M., Gino, F. and Bradley, S. R. (2013). 'Reinventing Employee Onboarding', MIT Sloan Management Review, 54(3), 22-29. doi: 10.1002/psb.423.

Daskalaki, M. (2012). 'Recontextualizing new employee induction: Organizational entry as a change space', Journal of Applied Behavioral Science, 48(1), 93-114. doi: 10.1177/0021886310395899.

Davies, A., Macaulay, S., Debarro, T., Thurston, M. et al. (2015). 'Making innovation happen in a megaproject: London's crossrail suburban railway system', Project Management Journal, 45(6), 25-37. doi: 10.1002/pmj.21461.

de Oliveira, S. N. et al. (2015). 'Experiential learning in nursing consultation education via clinical simulation with actors: action research', Nurse education today, e50-e54. doi: 10.1016/j.nedt.2014.12.016 LK.

Finn, R. (2014). "Better than the Real Thing? -Actor role-plays as part of Vocational Training”. In: Conference Proceedings Sino/Nz Tvet Educational Research Forum- Tianjin, China, 109-116.

Fry, H., Ketteridge, S., \& Marshall, S. (2014). Handbook for teaching and learning in higher education: Enhancing Academic Practice (4th ed.). Oxon, UK: Routledge.

Fuller, P., Gibb, A., Jones, W., Dainty, A., Haslam, R., Bust, P. and Pinder, J. (2017). Is the longbow better than the crossbow? Emerging issues from mobilising a longitudinal study on a megaproject. Journal of Construction Project Management and Innovation, 7(2), 20542065.

Graybill, J. O., Carpenter, M. T. H., Offord, J., Piorun, M. and Shaffer, G. (2013). 'Employee onboarding: Identification of best practices in ACRL libraries', Library Management, 200218. doi: 10.1108/01435121311310897. Hamblin, A. C. (1974). Evaluation and Control of Training. McGraw-Hill.

Haslam, R. A. et al. (2005). 'Contributing factors in construction accidents.', Applied ergonomics, 36(4), pp. 401-15. doi: 10.1016/j.apergo.2004.12.002.

Harvey, E. J., Waterson, P. and Dainty, A. R. J. (2018). 'Beyond ConCA: Rethinking Causality and Construction Accidents', Applied Ergonomics, 73, pp. 108-121. Available at: 10.1016/j.apergo.2018.06.001.

Horwath, J. and Morrison, M. (1999). Effective Staff Training in Social Care: From Theory to Practice. London, UK: Routledge.

Holton, E. F. (1996). The flawed four-level evaluation model. Human Resource Development Quarterly, 7(1), 5-21.

Kassab, E. S., King, D., Hull, L. M., Arora, S., Sevdalis, N., Kneebone, R. L., and Nestel, D. (2010). "Actor training for surgical team simulations". Medical teacher, 32(3), 256- 258. 
Kaufman, R., Keller, J. M., \& Watkins, R. (1995). What works and what doesn't: Evaluation beyond Kirkpatrick. Performance and Instruction, 35(2), 8-12.

Keltner, N. L., Grant, J. S., and McLernon, D. (2011). "Use of actors as standardized psychiatric patients: Facilitating success in simulation experiences". Journal of Psychosocial Nursing and Mental Health Services, 49(5), 34-40.

Kearns, P., \& Miller, T. (1997). Measuring the impact of training and development on the bottom line. FT Management Breifings. London: Pitman Publishing.

Kirkpatrick D.L. (1959). Techniques for evaluating training programs. Journal of American Society of Training Directors, 13(3), 21-26.

Kirkpatrick, D. L., \& Kirkpatrick, J. D. (2006). Evaluating Training Programs (3rd ed.). San Francisco, CA: Berrett-Koehler Publishers, Inc.

Kirkpatrick, J., \& Kirkpatrick, W. K. (2009). The Kirkpatrick Four Levels: A Fresh Look After 50 Years. Newnan, GA. Retrieved from http://www.kirkpatrickpartners.com/Portals/0/Storage/Kirkpatrick Four Levels white paper updated 10 09.pdf

Klein, H. J., Polin, B. and Leigh Sutton, K. (2015). 'Specific Onboarding Practices for the Socialization of New Employees', International Journal of Selection and Assessment, 23(3), 263-283. doi: 10.1111/ijsa.12113.

Kolb, D. A. (1987). Experiential Learning: Experience as the source of learning and development. Englewood Cliffs, NJ: Prentice-Hall.

Kraiger, K., \& Aguinis, H. (2013). Training effectiveness: Assessing training needs, motivation, and accomplishments. In M. London (Ed.), How to Evaluate Others in Organizations (pp. 203-220). Oxon, UK: Taylor and Francis Ltd.

Langford, D., Rowlinson, S., \& Sawacha, E. (2000). Safety behaviour and safety management: its influence on the attitudes of workers in the UK construction industry. Engineering, Construction and Architectural Management, 7(2), 133-140.

Lee-Kelley, L. (2018). 'When "knowing what" is not enough: Role of organised simulations for developing effective practice', International Journal of Project Management, pp. 198-207. doi: 10.1016/j.ijproman.2017.08.003.

Levitt, R. E., and Samuelson, N. M. (1993). Construction safety management, Wiley, New York.

Lexton, A., Smith, M., Olufemi, D., and Poole, G. (2005). "Taking a risk and playing it safe: The use of actors in interagency child protection training". Child Abuse Review, 14(3), 195206.

Louis, M. R. (1980). 'Surprise and Sense Making: What Newcomers Experience in Entering Unfamiliar Organizational Settings', Administrative Science Quarterly, 25(2), 226-251. doi: $10.2307 / 2392453$.

Lundin, R. A., \& Söderholm, A. (1995). A theory of the temporary organization. Scandinavian Journal of management, 11(4), 437-455. Chicago

Mohamed, S. (1999). Empirical investigation of construction safety management activities and performance in Australia. Safety Science, 33(3), 129-142. 
Moore, G., Audrey, S., Barker, M., Bond, L., Bonell, C., Hardeman, W., Moore, L., O'Cathain, A., Tannaze, T., Wight, D. and Baird, J. (2014). Process evaluation of complex interventions. London, UK. Retrieved from https://mrc.ukri.org/documents/pdf/mrc-phsrnprocess-evaluation-guidance-final/

Nestel, D. F., Black, S. A., Kneebone, R. L., Wetzel, C. M., Thomas, P., Wolfe, J. H., and Wetzel, C. M. (2008). "Simulated anaesthetists in high fidelity simulations for surgical training: feasibility of a training programme for actors". Medical Teacher, 30(4), 407-413.

Newby, A. C. (1992). Training Evaluation Handbook. Gower.

NICE. (2007). Behaviour change: general approaches. Retrieved from https://www.nice.org.uk/guidance/ph6/resources/behaviour-change-general-approaches-pdf55457515717

O'Conner, P., Flin, R., Fletcher, G., \& Hemsley, P. (2002). Methods used to Evaluate the Effectiveness of Flightcrew CRM Training in the UK Aviation Industry. Human Factors and Aerospace Safety, 2, 235-255.

Petracchi, H. E. (1999). "Using professionally trained actors in social work role-play simulations". Journal of Sociology and Social Welfare, 26, 61-69.

Pettigrew, A.M., (1992). The character and significance of strategy process research. Strategic management journal, 13(S2), 5-16.

Phillips, C., Esterman, A. and Kenny, A. (2015). 'The theory of organisational socialisation and its potential for improving transition experiences for new graduate nurses', Nurse Education Today. Elsevier B.V., 35(1), pp. 118-124. doi: 10.1016/j.nedt.2014.07.011.

Phillips, J., \& Holton, E. (1995). In Action: Measuring Return on Investment, Vol. 1.

Pink, S., Tutt, D., Dainty, A., and Gibb, A. (2010). "Ethnographic methodologies for construction research: knowing, practice and interventions". Building Research \& Information, 38(6), 647-659.

Pulley, M. L. (1994). Navigating the evaluation rapids. Training and Development, 48(9), 16 24.

Sawacha, E., Naoum, S., \& Fong, D. (1999). Factors affecting safety performance on construction sites. International journal of project management, 17(5), 309-315.

Sergeeva, N. and Zanello, C. (2018) 'Championing and promoting innovation in UK megaprojects', International Journal of Project Management, 36(8), 1068-1081. doi: 10.1016/j.ijproman.2018.09.002.

Stufflebeam, D. L. (2003). The CIPP Model for Evaluation. In International Handbook of Educational Evaluation, 31-62. Dordrecht: Springer Netherlands.

https://doi.org/10.1007/978-94-010-0309-4_4

Tamkin, P., Yarnall, J., \& Kerrin, M. (2002). Kirkpatrick and Beyond: A review of models of training evaluation. Brighton, UK. Retrieved from https://www.employmentstudies.co.uk/system/files/resources/files/392.pdf

The Scottish Government. (2015). Designing and Evaluating Behaviour Change Interventions. Edinburgh, UK. Retrieved from https://www.gov.scot/binaries/content/documents/govscot/publications/guidance/2015/03/de signing-evaluating-behaviour-change-interventions/documents/00472843-pdf/00472843pdf/govscot\%3Adocument 
Van Maanen, J. and Schein, E. H. (1979) 'Toward a theory of organizational socialization', Research in organizational behavior, 1, 209-264. doi: 10.2307/3760213.

Warr, P. B., Allan, C., \& Birdi, K. (1999). Predicting three levels of training outcome. Journal of Occupational and Organizational Psychology, 1(72), 351-375.

Warr, P. B., Bird, M., \& Rackham, N. (1970). The Evaluation of Training. Gower.

Waterson, P. (2015). 'Sociotechnical design of Work Systems', in Wilson, J. R. and Sharples, S. (eds) Evaluation of Human Work. 4th edn. Boca Raton, FL: CRC Press, pp. 753-772.

Wilson, H. J. (2000). "An integrated approach to consultation coaching using professional actors as simulated patients". Medical Teacher, 22(4), 370-379.

Wilson, C. (2012). Retaining good people through a focus on talent and purpose: Proper inductions make employees feel as though they truly belong. Human Resource Management International Digest, 20(2), 29-31. doi: 10.1108/09670731211208175.

Wilson, J. R. (2014). 'Fundamentals of systems ergonomics/human factors.', Applied ergonomics, 45(1), pp. 5-13. doi: 10.1016/j.apergo.2013.03.021.

Wustemann, L. (2015). Tideway Tunnel Vision, Heath+Safety at Work. Available at: https://www.healthandsafetyatwork.com/construction/tideway-tunnel-vision. 